\title{
Planejamento Territorial de Áreas Rurais em Contexto Metropolitano: O CASO DA REGIÃO METROPOLITANA DE GOIÂNIA
}

\author{
Territorial Planning of Rural Areas in the Metropolitan Context: \\ THE CASE OF THE METROPOLITAN REGION OF GOIÂNIA
}

\author{
iD Cristiane Moreira de Oliveira \\ Universidade Federal de Goiás, Goiânia, GO, Brasil. \\ cristiane.engenharia1@gmail.com \\ iD) 0 \\ David A. Finotti C. de Azerêdo \\ Universidade Federal de Goiás, Goiânia, GO, Brasil. \\ finotti_david@discente.ufg.br
}
0
Hugo José Ribeiro
Universidade Federal de Goiás, Goiânia, GO, Brasil. hgribeirogeo@gmail.com
iD 0
Karla Emmanuela R. Hora
Universidade Federal de Goiás, Goiânia, GO, Brasil. karla_hora@ufg.br

\section{Resumo}

O modelo de desenvolvimento urbano acelerado e desassociado de uma preocupação com o planejamento socioambiental para as cidades acumulou diferentes impactos negativos de difícil mediação sobre o uso e ocupação do solo na relação urbano-rural. Caberia ao Plano Diretor Municipal (PDM) apresentar as diretrizes de ordenamento sobre o território, incluindo as atividades desenvolvidas no meio rural. Entretanto, a pressão latente pela ampliação da mancha urbana, desconsiderou a importância das áreas rurais. Considerando tal contexto o objetivo dessa reflexão é identificar como as áreas rurais são retratadas nos planos diretores e como isto se reflete no contexto da expansão da mancha urbana sobre o território. A análise considerou o caso da Região Metropolitana de Goiânia (RMG). A metodologia baseou-se na análise dos Planos Diretores e no 
uso de geotecnologias para mapeamento da malha urbana. Os resultados indicam uma menção genérica de diretrizes sobre as áreas rurais nas normativas analisadas e a crescente expansão da mancha urbana em detrimento de um planejamento integrado que considere as áreas rurais sob a perspectiva do compartilhamento das funções de uso comum no contexto metropolitano.

Palavras-chave: Rural Metropolitano. Recursos Hídricos. Plano Diretor. RMG. Estatuto da Metrópole.

\section{Abstract}

The accelerated urban development model dissociated from a concern with socio-environmental planning for cities has accumulated different negative impacts that are difficult to mediate on land use and occupation in the urban-rural relationship. It would be incumbent on the Master Plan (PD) to present the directives and ordering of the territory, including the activities carried out in rural areas. However, the latent pressure for the expansion of the urban sprawl ignored the importance of rural areas. Considering this context, the objective of this reflection is to identify how rural areas are portrayed in the master plans and how this is reflected in the context of the expansion of the urban sprawl over the territory. The analysis considered the case of the Metropolitan Region of Goiânia (RMG). The methodology was based on the analysis of Master Plans and the use of geotechnologies for mapping the urban fabric. The results indicate the generic mention of guidelines on rural areas in the analyzed regulations and the growing expansion of the urban sprawl to the detriment of an integrated planning that considers rural areas from the perspective of sharing common use functions in the metropolitan context.

Keywords: Metropolitan Rural. Water Resources. Master plan. RMG. Statute of the Metropolis. 


\section{Introdução}

O modelo de desenvolvimento urbano acelerado e desassociado de uma preocupação com o planejamento socioambiental para as cidades acumulou diferentes impactos negativos de difícil mediação sobre o uso e ocupação do solo na relação urbano-rural. Com a Constituição Federal de 1988 e a promulgação do Estatuo das Cidades, Lei $n^{\circ} 10.257$ de 10 de julho de 2001, revigorou-se a importância do Plano Diretor Municipal (PDM) como instrumento básico da política de desenvolvimento e de ordenamento territorial, abrangendo orientações para a expansão urbana e incluindo as áreas rurais. Importante salientar que as áreas rurais, até então, não eram inseridas nos planos diretores de forma efetiva, fazendo com que a expansão urbana as incorporasse sem uma discussão maior sobre esse território.

A aprovação do Estatuto das Metrópoles, Lei $n^{\circ}$ 13.089, de 12 de janeiro de 2015, trouxe uma nova perspectiva para o planejamento metropolitano e para o delineamento dos usos pretendidos nas áreas rurais neste contexto. A abrangência da lei aponta a necessidade de diretrizes gerais para o planejamento, execução, e gestão das funções públicas de interesse comum em regiões metropolitanas, apresentando uma nova visão para as áreas metropolitanas e abrindo nova perspectiva de gestão sobre as áreas de transição urbano-rural. Essa perspectiva, abriu uma brecha para recuperar a dimensão de multifuncionalidade do rural sob a perspectiva ambiental (HORA, 2017).

O Plano de Desenvolvimento Integrado Metropolitano, ao se tornar uma ferramenta para a gestão integrada dos municípios, também, possibilita um olhar diferenciado sobre as áreas rurais considerando a possibilidade dos múltiplos usos e das múltiplas funções (CONCEIÇÃO, 2020). Salienta-se que, é nas áreas rurais que se encontram grandes fragmentos florestais, reservas minerais, sítios de recreação e lazer rural, turismo rural e as fontes de águas dos principais cursos d'água que abastecem as cidades. A ausência de diretrizes para as áreas rurais nos instrumentos de planejamento urbano, desconhecem a importância destas áreas para o microclima, para o sistema de abastecimento alimentar e redução da pegada de carbono nesse 
ciclo, e a manutenção da paisagem com fins de serviços ambientais. Além, é claro, do reconhecimento aos diferentes modos de vida que estão ali inseridos e compreendem, por vezes, culturas diversas, tais como aquelas inerentes aos Povos e Comunidades Tradicionais.

A relevância em compreender os territórios rurais de forma ativa, colaborativa e não subordinada ao urbano, deve ser tratada, também, sob a perspectiva da inclusão e justiça socioambiental. Os territórios rurais podem receber tipologias de parcelamento diversos, tais como os capitaneados pela reforma agrária, contribuindo com os sistemas socioecológicos de produção de alimentos sob um modelo diferenciado (YAMILLA, 2007). Ainda, a proximidade produtor-consumidor pode potencializar outras relações de consumo em regiões urbanizadas (HORA et al, 2007).

Considerando tal contexto o objetivo dessa reflexão é identificar como as áreas rurais são retratadas nos planos diretores e como isto se reflete no contexto da expansão da mancha urbana sobre o território metropolitano. A análise considerou o caso da Região Metropolitana de Goiânia (RMG).

A singularidade das áreas rurais e a grande densidade de parcelas do território da RMG geram um desequilíbrio nas relações socioambientais com a urbanização da pobreza, ocupação irregular, degradação ambiental, déficit habitacional urbano e demais implicações que colocam as práticas de planejamento integradas no limbo. Para Deus e Barreira (2015, pg. 4) as soluções de interesse comum, preconizadas pelo Estatuto da Metrópoles, deveriam "ser estrategicamente articuladas no espaço metropolitano visando o desenvolvimento regional e a desejável redução das desigualdades".

O reconhecimento do conjunto de funções comuns com o destino de áreas adequadas para a prática da agricultura e as múltiplas funções das áreas rurais em regiões metropolitanas, permite redimensionar e requalificar a relação urbana-rural sob uma perspectiva de interdependência e coexistência. Não se trata, apenas, de uma redefinição de escala geográfica e limite territorial, mas pressupõe uma reflexão e direcionamento dos usos, de caráter relacional e de qualidade socioambiental destes 
territórios que podem ser protegidos e potencializados gerando novas dinâmicas urbanas-rurais. (HORA, 2017).

No contexto das ferramentas de planejamento ambiental e territorial, as áreas rurais deveriam ser melhor compreendidas no contexto metropolitano, com diretrizes que incorporassem, não só a valorização econômica e ambiental, mas também o uso de seu território sob uma perspectiva de desenvolvimento rural metropolitano.

\section{Distinções significativas e relativas entre áreas urbanas e rurais}

As transformações do mundo rural e de sua relação com o urbano provocou a revisão de hipóteses e conceitos para entender essa nova realidade que se apresentava nas últimas décadas do século XX. O rural não desapareceu e sua existência, ou renascimento, num mundo altamente urbanizado, não eliminou a relevância das áreas rurais, da mesma forma que estas não mais se circunscreveram ao papel prioritário de produção de bens primários.

Maria Wanderley (2000), destaca que o 'rural' como um objeto singular e que deve ser analisado a partir dos processos que o transformaram. Enquanto território e espaço de vida ele não está incólume às novas dinâmicas da sociedade urbanaindustrial, mas ele também se destaca sob novos pressupostos de ruralidade, que aponta para novos processos sociais.

Graziano da Silva, também observou as transformações do mundo rural. No Projeto Rurbano que estudou o meio rural brasileiro entre 1992 a 1998, o autor alertou para a existência de inúmeras atividades não-agrícolas nessas áreas, indicando que o rural era muito maior que o agrícola (GRAZIANO SILVA, 2002). Para Graziano Silva (2002) o rural pode ser compreendido como um continuum do urbano, uma vez que teria se urbanizado como resultado da industrialização da agricultura. Nos aspectos econômicos, fica cada vez mais significativa a presença de serviços no campo. Estes são oferecidos, principalmente, para atender a uma demanda educacional e turística 
do meio urbano, representada por: feiras de artesanato e de gastronomia locais, festas religiosas e escolas relacionadas à temática da agroecologia (SILVA, 2000).

Para Kozenieski e Medeiros (2018), ao analisar o conjunto de transformações ocorridas no Brasil, último XX, deve-se compreender as funções econômicas, com a influência da industrialização e das dinâmicas populacionais, que proporcionaram o aumento da população urbana em detrimento da rural, a partir de meados da década de 1960. O crescimento das cidades acentuou, significativamente, a concentração urbana, e o êxodo rural e contribuiu para a extensão do tecido urbano. Assim, as áreas limítrofes aos núcleos urbanos centrais tornaram-se receptáculos da expansão da cidade. Nesse sentido, os espaços que antes eram destinados à produção de alimentos foram destinados a edificações, como a construção de moradias, entre outras finalidades, demonstrando a profunda transformação da relação entre o urbano e o rural (KOZENIESKI; MEDEIROS, 2018).

Outro aspecto que demonstra a profunda relação entre o campo e a cidade é a existência de "municípios rurais", os quais, apesarem de serem considerados espaços urbanizados, possuem uma organização social, econômica, política e cultural voltada para o âmbito rural (VEIGA, 2002).

Alentejano (2003) afirmava que, no início do século XXI, as interpretações sobre o mundo rural encontravam-se numa encruzilhada. Colocavam-se novas questões sobre sua permanência ao mesmo tempo que sua definição administrativa era questionada. O fato é que a permanência e transformação do mundo rural levou a novas abordagens sobre o seu lugar na sociedade contemporânea. Denotou-se, então, o crescimento e a relevância dos estudos sobre o novo mundo rural e as novas ruralidades, cujas releituras apontaram as múltiplas funções na agricultura (CAMARGO; OLIVEIRA, 2012) e abordagens sobre desenvolvimento rural (FAVARETO, 2010).

As análises sobre a problemática ambiental, emergentes a partir década de 1960, também encontram locus nas discussões sobre o mundo rural, com destaque para as análises sobre o impacto do processo de produção da agricultura sobre a natureza (ZARREF, 2017), nos estudos sobre modelos de produção alternativos, com 
ênfase na agroecologia (ASSIS, 2006), ou nos estudos sobre preservação ambiental (PÁDUA, 1999). Do ponto de vista das diferenciações espaciais destaca-se o estudo de Sorokin, Zimmerman e Galpin (1981) sobre as distinções urbano-rural; enquanto Veiga (2003) explana sobre as limitações da classificação entre urbano e rural no Brasil e documentos do Instituto Brasileiro de Geografia e Estatística (IBGE) (IBGE, 2017) apontam nova possibilidade de classificação e caracterização dos espaços rurais e urbanos do Brasil, considerando tipologias de ocupação.

As análises do rural sob uma perspectiva ambiental imputaram novas funções para esse na relação campo-cidade. As áreas rurais em regiões altamente urbanizadas ou metropolitanas foram analisadas sob a lógica da expansão urbana ou dos instrumentos de conservação ambiental para fins de preservação de recursos naturais, com destaque para os mananciais de abastecimento. Essa visão reducionista do papel do rural é, comumentemente, vista nos instrumentos de planejamento e gestão urbanas. Não obstante, de diferentes formas, principalmente nos contextos urbanizados, as áreas rurais foram se reconstituindo sob o vazio demográfico, porém lesadas pelo passivo ambiental oriundos do modelo de produção agrícola avançado (HORA, et al. 2007).

Maluf (2004) retoma a importância do planejamento das áreas rurais sob a perspectiva da segurança alimentar e nutricional (SAN), destacando a importância da articulação dos Planos Diretores com a Políticas Municipal de SAN. Enquanto Nakano (2004) e Saule Jr. (2004) reforçam a necessidade da releitura da dinâmica socioterritorial e na perspectiva da sustentabilidade ambiental.

Para Dias (2012), a expansão urbana que vêm avançando para áreas rurais as alteram ou até mesmo as destroem, acompanhada da degradação da própria realidade urbanística e da qualidade de vida. Assim, as cidades se desenvolvem, expandem, reproduzem-se sob a lógica de acumulação capitalista (re)valorizando os espaços rurais, mas sob a mesma lógica da urbanização; produzindo mazelas, degradação ambiental e desigualdades sociais. Essa transformação, ao mesmo tempo que revigora o rural, o corrói. 
Os Planos Diretores Municipais revelam poucas preocupações, em termos institucionais e normativos, com o planejamento territorial das áreas rurais. Para Braga (1995) desconsiderar o meio rural no Plano Diretor seria uma falha capaz de inviabilizar sua aplicação, principalmente tratando-se de municípios, como o caso dos municípios paulistas, de médio e pequeno porte de economia predominante agroindustrial ou agropecuária.

Não por acaso, torna-se simbólico o caso da cidade de São Paulo, mais cidade do país. O Plano Diretor Estratégico de 2014 da cidade, reinstituiu as zonas rurais, abolidas no plano de 2002, ocupando 25\% de sua área total (CARDOSO; EMIPONTTI; TRAVASSO, 2017). Assim, a cidade de maior região metropolitana do Brasil enquadrase em diferentes discussões referente às funções que podem ser atribuídas as áreas rurais, relacionando a atividades não somente agropecuárias, mas também pela diversidade social e singularidade ambiental destas áreas (HORA, 2017).

Entretanto, faz-se necessário compreender a pontar para certa classificação funcional ao se delimitar o que é rural do que é urbano. Spavorek, Leonelli e Barreto (2004) chamam atenção para o fato de que no urbano os serviços, atividades industriais e comerciais, redes de infraestrutura são contínuas e consolidadas, propriedades imobiliárias fragmentadas e alta densidade populacional permite ao urbano o reconhecimento pela ampla oferta de serviços públicos, podendo existir ou não produção agrícola. Enquanto no rural os equipamentos públicos e a extensão dos serviços são parciais e restritos, a grandeza das propriedades é maior predominando atividades de preservação agrícolas a presença de loteamentos e condomínios, no entanto não há continuidade espacial entre eles (SPAROVEK; LEONELLI; BARRETTO, 2004).

Nas franjas urbanas, há que se considerar uma certa dinamicidade que impede uma classificação rígida destas funcionalidades. A pressão sobre a terra, considerando a demanda habitacional e o custo da terra urbana podem inviabilizar certas atividades agrícolas, e levar ao parcelamento de pequenos lotes urbanos. Por outro lado, a permanência da produção de hortifrúti no entorno das cidades pode contribuir na 
oferta de alimentos com menor custo de produção e mais acessível à população. Por isso, há que se considerar a possibilidade de criação de zonas com atividades de uso misto urbano-rural sob uma perspectiva de segurança alimentar.

\section{Qual o lugar das áreas rurais nos instrumentos institucionais de planejamento urbano e ambiental?}

O planejamento pressupõe uma atividade de antecipação mental de problemas e até a proposição de cenários com possíveis soluções. Para Drucker (2002) significa antecipar o futuro com decisões no presente. Ao se considerar o planejamento ambiental, Santos (2004) indica que sua finalidade considera, também, ações que possam garantir o desenvolvimento das sociedades, analisando de forma sistêmica as informações, métodos e procedimentos de forma a aperfeiçoar as alternativas para aproveitamento dos recursos.

Considerado um processo metódico e sistemático, o planejamento envolve organização, coleta e análise de dados e produção de informações, com a utilização de técnicas e métodos variados, ou seja, é um processo contínuo e se dá "por meio de procedimentos e métodos, para se chegar a decisões ou escolhas acerca das melhores alternativas para o aproveitamento dos recursos disponíveis" (SANTOS, 2004, p.24). Em resumo, ele pressupõe conhecer a realidade sobre a qual se está tratando, produzir sínteses sobre ela identificando possibilidades e limites, apontar aspectos futuros seja diretrizes seja ações pragmáticas na forma de programas e projetos.

O planejamento direciona os instrumentos legislativos, administrativos e de gestão contribuindo para o desenvolvimento das atividades das áreas urbanas e rurais, permitindo que a comunidade participe juntamente com as instituições, integrando as relações entre sociedade e autoridades locais. Para fins de monitoramento e avaliação, a definição de indicadores e elementos paramétricos possibilitam a avaliação temporal dos resultados dos planos, facilitando a ação pública. 
Em termos da política urbana, o planejamento das cidades e seu território deve considerar não só a interferência das múltiplas escalas - local e regional - como também, aspectos setoriais, além da delimitação urbana-rural e instrumentos de planejamento ambiental (BRASIL, 2014). Sob o aspecto da dimensão territorial do planejamento, a compreensão da problemática ambiental torna-se fundamental para minimizar os impactos causados pelo uso e ocupação das cidades (LIMA et al., 2016).

O Estatuto da Cidade (Lei Federal $n^{\circ}$ 10.257/01) indica no artigo 4, inciso III os principais instrumentos para o planejamento municipal, a saber: os planos diretores, parcelamento de uso e ocupação do solo, zoneamento ambiental, planos de desenvolvimento econômico social dentre outros instrumentos de gestão (BRASIL, 2001). Outros instrumentos de gestão também afetam o planejamento no município, tais como a Lei Orgânica, o Código Tributário, o Código de Posturas e o Código de Obra (LIMA et al. (2016). Da mesma foram que os instrumentos de planejamento ambiental, tais como, o Zoneamento Ecológico e Econômico (ZEE) e Plano de Bacia Hidrográfica $(\mathrm{PBH})$ afetam a definição das atividades nas áreas rurais sob o viés da sustentabilidade ambiental nos territórios, sendo estes, especialmente, importante para as áreas rurais, já que incidem sobre a definição do tipo de uso da terra que se terá como expectativa para cada local.

No caso do ZEE, que é instrumento da Política Nacional de Meio Ambiente, Decreto $n^{\circ} 4.297$, de 10 de julho de 2002, espera-se que o mesmo indique "diretrizes para racionalização do uso do território buscando reorientar atividades para o desenvolvimento econômico e ecológico" (FERREIR; SANTOS, 2011, p.26). O Plano de Bacias Hidrográficas, por sua vez, previsto na Política Nacional de Recursos Hídricos (PNRH) - Lei No 9.433, 8 de janeiro de 1997, estabelece diretrizes, mediante diagnóstico da região de uma bacia hidrográfica e visa a mediação necessária para a utilização dos recursos hídricos. Assim, tanto a PNMA, quanto a PNRH apresentam instrumentos de planejamento que afetam sobremaneira o desenvolvimento socioeconômicos dos espaços rurais. 
Logo, em termos de planejamento no município, as diferentes esferas do planejamento e suas múltiplas escalas devem ser equacionadas visando que não haja contradições nos usos e diretrizes, de tal que forma que se adote uma sinergia nas ações e a otimização dos recursos para programas que promovam o desenvolvimento dos territórios.

Para Luft (2010), a elaboração do Plano Diretor deve apresentar os traços da realidade social e espacial na qual sobrevém o planejamento e projetar o futuro do desenvolvimento das cidades. Contudo, embora as diferentes políticas atuem sobre o território e impactem as áreas rurais de diferentes formas, a gestão do território rural é multifacetada e dividida entre os diferentes entes federativos. $E$, mesmo que a destinação de usos deste espaço esteja condicionada ao cumprimento da função social da terra estabelecida no Estatuto da Terra (Lei no 4504 de 30 de novembro de 1964) e na Constituição Federal de 1988, o seu planejamento ainda é débil.

Na teoria, tem-se a importância do Plano Diretor como o instrumento macro de ordenamento do território do município, abrangendo, inclusive, as áreas rurais. $\mathrm{Na}$ prática, o Plano Diretor pouco orienta o ordenamento do solo rural, dado os inúmeros dispositivos legais que atuam sobre esse território (HORA, 2017). Reflexão corroborada por Mesquita e Ferreira (2016, pg.2) que indicam que "até fins do século XX apenas com o planejamento urbano, tratando de forma incipiente ou mesmo inexistente, o planejamento do espaço rural, o qual foi inserido nesse documento somente após a promulgação do Estatuto da Cidade em 2001, ainda assim, de forma superficial".

Chama atenção o caso recente do Plano Diretor Estratégico do Estado de São Paulo, disposto na Lei Municipal n 16.050/14 (SÃO PAULO, 2014), cuja reincorporação das áreas rurais ficou associada a uma perspectiva de desenvolvimento sustentável, incentivando usos sustentáveis, tais como a agricultura orgânica, contenção da expansão urbana e preservação de ecossistemas naturais. As diretrizes e ações aplicadas a áreas rurais são identificas no PDE (Lei $n^{\circ}$ 16.050/14) entre os artigos 190 e 192 referenciando as atividades agrícolas. Chama atenção, nesse plano, a proposição do Plano Municipal de Desenvolvimento Rural Sustentável no artigo 190. 
Contudo, tal prática não é comum se ver nos Planos Diretores Municipais.

\section{Metodologia}

Para o delineamento desse estudo, três etapas foram necessárias. A primeira referiu-se à revisão bibliográfica. Esta concentrou-se em identificar artigos que abordam o estudo de planejamento de áreas rurais metropolitanas ou na relação urbano-rural. Logo, nesta etapa, realizou-se a busca na internet de dissertações, artigos e demais documentos que trouxesse informações sobre o tema deste trabalho, através das palavras-chave: planejamento ambiental, áreas rurais metropolitanas, planejamento de áreas rurais, transição urbano-rural. A busca deu-se na plataforma de periódicos da CAPES com preferência para textos dos últimos 20 anos.

A segunda etapa baseou-se na pesquisa documental. Neste caso, buscouse identificar a base legal que ancora diretrizes e instrumentos para o planejamento das áreas rurais no âmbito Federal, Estadual, Municipal e Metropolitano, resultando num inventário. Esta etapa consistiu-se em dois momentos: o primeiro identificou-se legislações Federal e Estadual e, posteriormente, identificou-se as diretrizes que os Planos Diretores Municipais da RMG apresentavam sobre as áreas rurais. Neste caso observou-se que tipo de menção foi feita sobre a área rural e qual possível implicação poderia ter no contexto metropolitano. Para isto, considerou-se, principalmente, os efeitos da expansão da mancha urbana sobre as bacias de captação de água a partir do estudo de Nunes (2016) e Hora (2017), desenvolvidas na etapa três.

A terceira e última etapa considerou as mudanças quantitativas na delimitação da área rural por meio do mapeamento da mancha urbana. Para isto apoiou-se no uso de geotecnologias por meio do Sensoriamento Remoto (SR) e de tratamento de dados em ambientes de sistema de informação geográfica (SIG). Para Conceição (2004) as simulações desses efeitos de expansão urbana e ocupação territorial, através dos estudos de mapeamentos permite a criação de políticas públicas para gerar uma melhor qualidade de vida para sociedade. 
Assim, nessa etapa analisou-se a expansão da mancha urbana sobre as áreas rurais e sua correlação com aspectos demográficos. Para isto considerouse o período de 1991-2020 donde se extraiu dados de variação da população dos Censos Demográficos (1991; 2000; 2010 e estimativa populacional 2020) e utilizou-se imagens de sensoriamento remoto que indicassem a área urbanizada, disponíveis na plataforma do Sistema Estadual de Geoinformação, (http://www.sieg.go.gov.br/) e no portal MapBiomas (http://mapbiomas.org/).

Utilizou-se um software de Sistemas de Informações Geográficas (SIG), Software QGIS versão 3.2.3., para a organização, processamento e análise dos dados.

No Software QGIS, com os dados cartográficos, dos municípios do Estado de Goiás, foram obtidos através do portal SIEG, e realizado o recorte dos municípios que contemplam a Região Metropolitana de Goiânia.

As imagens de uso e ocupação do solo obtidas através do MapBiomas foram recortadas no QGIS considerando os limites da área correspondente a RMG, utilizando como referência a sobreposição da camada vetorial dos municípios da RMG. Desta forma, foi possível realizar a conversão do raster de cada ano em vetor. Após a poligonização do vetor, este novo shapefile foi classificado conforme código de classes do MapBiomas para uso e ocupação do solo, a classe 24, correspondente a Infraestrutura, criando o vetor de mancha urbana.

Para análise da área de infraestrutura urbana em cada município foi criado um novo campo denominado área, na tabela de atributos do vetor de mancha urbana, tendo como produto o cálculo da área geométrica de cada polígono $\mathrm{em} \mathrm{km}^{2}$. Posteriormente, foi feito o recorte do vetor da mancha urbana pela camada vetorial dos municípios da RMG, foi possível realizar o mapeamento da expansão das manchas urbanas na Região Metropolitana no intervalo de $10 \mathrm{em} 10$ anos no período de 1990 até 2020 para interpretação visual. Para os dados geográficos, em sua totalidade, foram aplicados a mesma projeção cartográfica, neste caso, Universal Transversa de Mercator, fuso 22 , Datum WGS-1984. 
Após a coleta de dados, o processo para confecção dos mapas temáticos da expansão da mancha urbana, e extração dos dados numéricos para esta análise, seguiu conforme o procedimento descrito na Figura 1.

Para análise numérica foi interseccionado as projeções cartográficas de mancha urbana de cada ano com a camada vetorial da RMG, e utilizado a calculadora de campo, do software QGIS, para cálculo da porcentagem da área da mancha urbana de cada município em relação a sua área total. Com estes valores organizados foi possível tabelar o percentual, área total da mancha urbana em cada município em cada ano analisado.

Figura 1 -Processo para tratamento e análise dos dados. Fonte: Elaborado pelos autores.

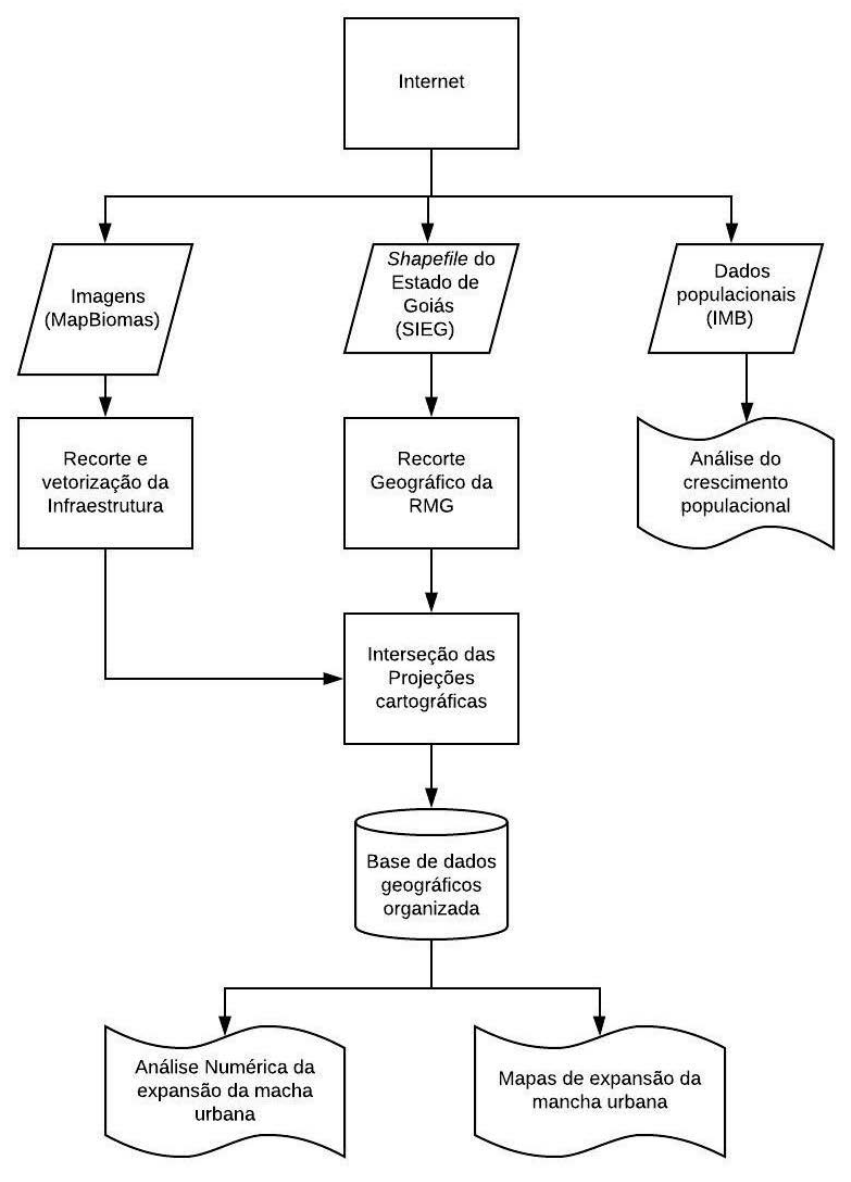

Com os dados censitários do IBGE tabelados de população total, urbana e rural dos municípios da RMG, obtidos através do portal do Instituto Brasileiro de Estatística e Geografia sendo possível analisar a dinâmica do crescimento da população da área urbana em relação a área rural.

\section{Resultados e Discussões}

A constituição da Região Metropolitana de Goiânia (RGM) deu-se em 1999 por meio da Lei Complementar Estadual no 27 de 30 de dezembro de 1999, que 
reorganizou o aglomerado urbano de Goiânia que, em 1980, era composto por oito municípios (IPEA, 2015). Em 2019, a Lei Complementar Estadual nº 149 de 15 de maio dava nova composição à RMG, com 21 municípios, sendo: Abadia de Goiás, Aparecida de Goiânia, Aragoiânia, Bela Vista de Goiás, Bonfinópolis, Brazabrantes, Caldazinha, Caturaí, Goianápolis, Goiânia, Goianira, Guapó, Hidrolândia, Inhumas, Nerópolis, Nova Veneza, Santa Bárbara de Goiás, Santo Antônio de Goiás, Senador Canedo, Terezópolis de Goiás e Trindade (GOIÁS, 2019). A Figura 2 apresenta a Região Metropolitana de Goiânia (RMG) (Figura 2) como objeto de estudo.

Em termos populacionais, verifica-se que o percentual em relação à população total é distinto, dos quais se destaca, para 2010, maior população rural em Caldazinha (43\%) e Hidrolândia (40\%), seguido de Aragoiânia (32\%). Nerópolis e Trindade apresentam 4\% de população rural cada e, Aparecida de Goiânia, Senador Canedo e Goiânia, apresentam valores inferiores a 1\% (IBGE, 2010). (Figura 3).

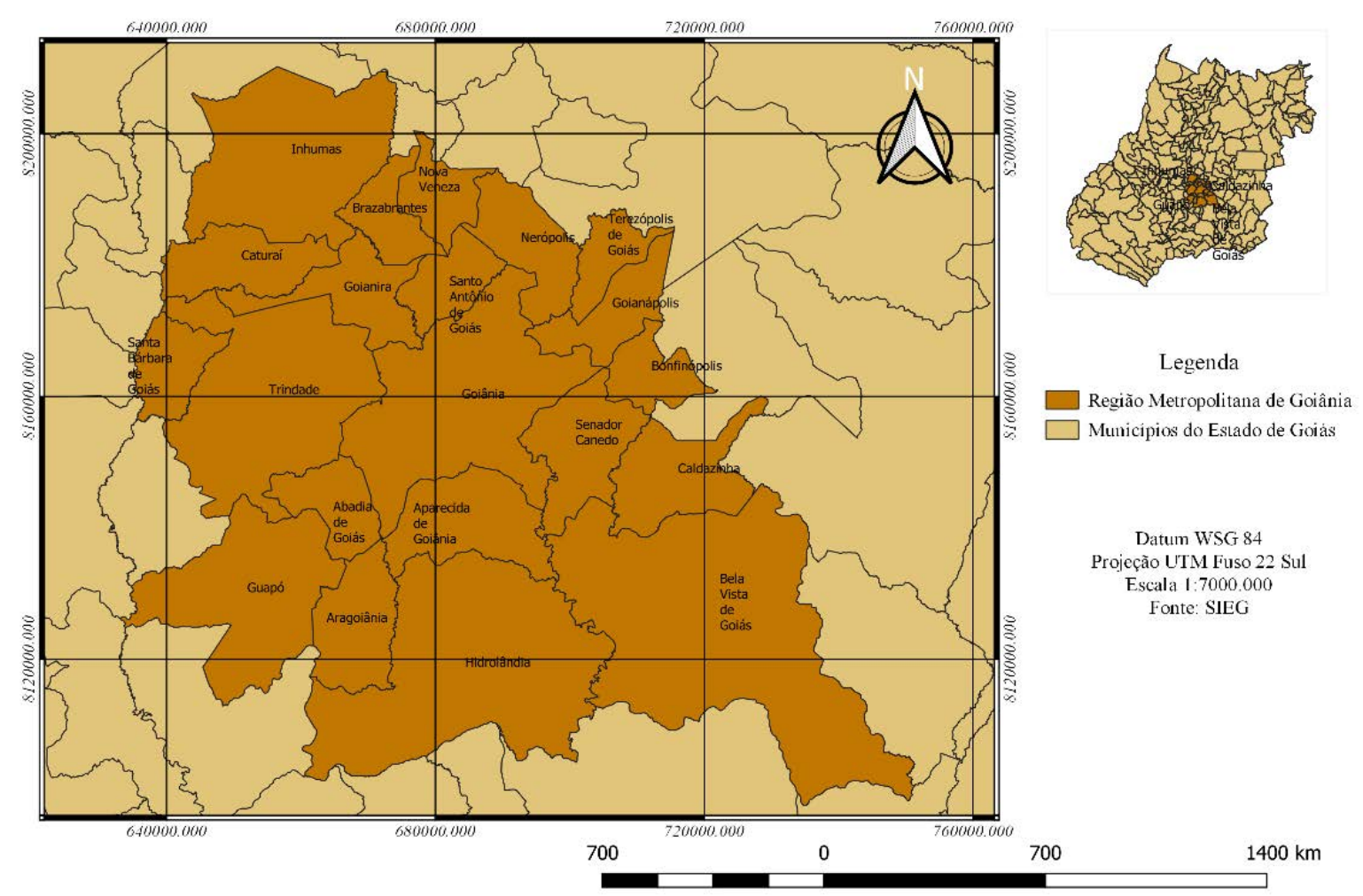

Figura 2 -Localização da Região Metropolitana de Goiânia. Fonte: Elaborado pelos autores. 


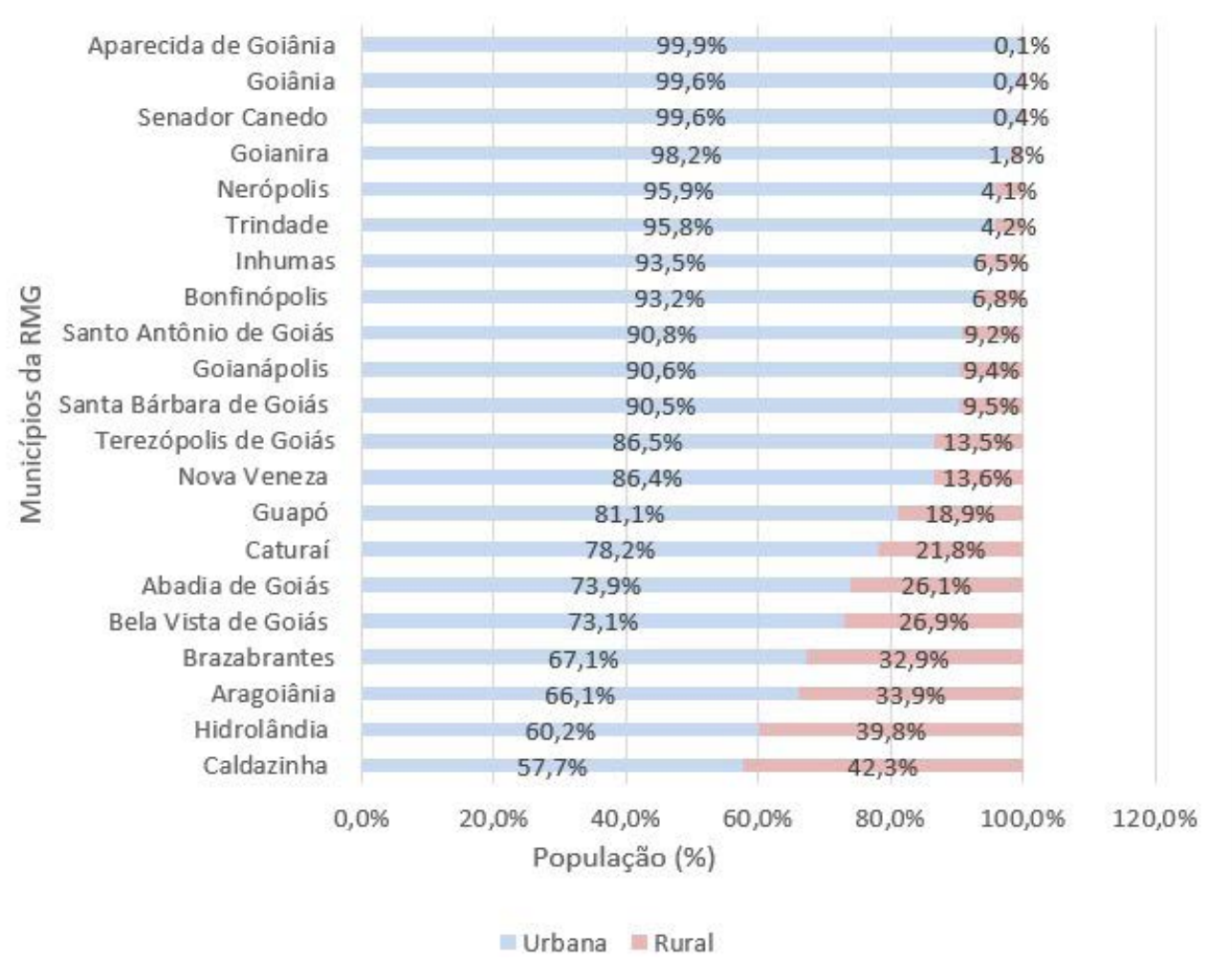

Figura 3 -População Urbana e Rural da RMG, 2010.

Fonte: IBGE, 2010. Adaptado.

A RMG, em 2010, abrangia 36,2\% de toda a população do Estado de Goiás, sendo que, Goiânia, Aparecida de Goiânia, Senador Canedo e Trindade respondia por 90\% do total (IBGE, 2010). Em 2010, significava cerca de 2,4 milhões de habitantes distribuídos numa área superior a $7 \mathrm{mil} \mathrm{km}^{2}$, das quais, 98,02\% moravam nas áreas urbanas. Em 2021, a estimativa populacional apontava para 2,7 milhões de habitantes em toda região.

\section{Como os Planos Diretores olham para as áreas rurais}

Parte-se do princípio que as estratégias do planejamento para o desenvolvimento das áreas rurais devam estar inseridas o Plano Diretor Municipal (PDM). Na RMG, dos 21 municípios, foi possível identificar 14 municípios com Plano Diretor.

Desses, destaca-se que Terezópolis de Goiás possui a minuta do Plano Diretor disponibilizada em ambiente virtual público. O município de Caldazinha tem informação pública em ambiente virtual do Ministério Público de Goiás, com data de 2016, sobre a 
Planejamento Territorial de Áreas Rurais em Contexto Metropolitano: o caso da RMG.

realização do Plano Diretor. Entretanto, o mesmo não está publicado no portal virtual da Prefeitura ou da Câmara Municipal.

O Município de Goiânia começou a revisão do Plano Diretor em 2017. Porém o mesmo foi retirado de tramitação na Câmara de Goiânia no segundo semestre de 2020. Os demais municípios que não apresentam informação na tabela, não possuem documento disponível nos seus ambientes virtuais públicos oficiais. (Quadro 1).

\begin{tabular}{|c|c|c|}
\hline $\mathbf{N}$ & Município da RMG & Lei do Plano Diretor \\
\hline 1 & Abadia de Goiás & Lei Complementar n॰03/2008 \\
\hline 2 & Aparecida de Goiânia & Lei Complementar n॰124/2016 \\
\hline 3 & Aragoiânia & - \\
\hline 4 & Bela Vista de Goiás & Lei Complementar $n \circ 32 / 2008$ \\
\hline 5 & Bonfinópolis & - \\
\hline 6 & Brazabrantes & - \\
\hline 7 & Caldazinha & - \\
\hline 8 & Caturaí & - \\
\hline 9 & Goianápolis & Lei n॰ 994/2003 \\
\hline 10 & Goiânia & Lei n॰171/2007 \\
\hline 11 & Goianira & Lei Complementar n॰ 05/2007 \\
\hline 12 & Guapó & Lei n॰12/2008 \\
\hline 13 & Hidrolândia & Lei n॰288/2006 \\
\hline 14 & Inhumas & Lei n॰2675/2007 \\
\hline 15 & Nerópolis & Lei n॰1472/2008 \\
\hline 16 & Nova Veneza & - \\
\hline 17 & Santa Bárbara de Goiás & Lei Complementar n॰1982/2020 \\
\hline 18 & Santo Antônio de Goiás & - \\
\hline 19 & Senador Canedo & Lei n॰1317/2007 \\
\hline 20 & Terezópolis de Goiás & Minuta de Lei de 2017 \\
\hline 21 & Trindade & Lei Complementar n॰ 08/2020 \\
\hline
\end{tabular}

Observando os Planos DiretoresMunicipais dosmunicípios da RMG, pode-se observar que a política de planejamento urbano contempla as áreas rurais de forma genérica. De forma geral identificase a falta de uma estratégia de desenvolvimento rural alicerçada no Plano Diretor.

Quadro 1 -Planos Diretores Municipais na RMG. Fonte: Elaborado pelos autores.

Observando os Planos Diretores Municipais dos municípios da RMG, pode-se observar que a política de planejamento urbano contempla as áreas rurais de forma genérica. De forma geral identifica-se a falta de uma estratégia de desenvolvimento rural alicerçada no Plano Diretor.

As diretrizes apresentadas nas leis relacionam-se, majoritariamente, com a questão ambiental e proteção de áreas permanentes. Questões referentes a proposições de ações para ruralidades, infraestrutura, pluriatividade ou fortalecimento 
de práticas culturais locais são incipientes ou inexistentes. Dos 14 documentos coletados, destacam-se alguns.

No Plano Diretor do município de Aparecida de Goiânia, por exemplo, é possível identificar que as áreas rurais seguem interesse urbano, como visto no Art. 95 "O Município, com base no interesse local poderá definir critérios restritivos de uso e ocupação do solo em Zona Rural, proibindo usos que signifiquem prejuízos ou repercussões indesejáveis, do ponto de vista urbanístico e de interesse público, na malha urbana" (APARECIDA DE GOIÂNIA, 2016). Destaca-se que, a mancha urbana no município, em 2010, correspondeu a 48,8\% do município e a população rural equivalia a menos de 500 habitantes.

No Plano Diretor de Hidrolândia, município que apresenta, proporcionalmente, maior população rural em relação aos outros municípios citados, observa-se tratamento diferente relacionado a áreas rurais. Na seção de desenvolvimento econômico Art.37 - Inciso V trata do "desenvolvimento das atividades rurais ou as desenvolvidas no meio rural, apoiando e fomentando o sistema de produção e comercialização, visando o desenvolvimento sustentável da atividade", nas normas específicas de zonas localizadas em território rural apresentam-se no que se dispõe do parcelamento, uso e ocupação do solo discorre os Art.104 e Art.105 - Inciso I "incentivos públicos para a implantação de empreendimentos voltados ao turismo rural e/ou ecoturismo" (HIDROLÂNDIA, 2006).

No Plano Diretor do município de Nerópolis observa-se estratégias socioambientais voltadas a áreas rurais, visto nos incisos do Art.100-C, como mostra inciso IV "adequar o ensino de alfabetização de adultos à formação profissional, com destaque para o manejo de máquinas agrícolas, de plantação, de confecção de subprodutos, de ordenha e manejo de gado, do turismo rural” (NERÓPOLIS, 2015).

No documento de revisão do Plano Diretor do município de Goiânia, até então disponível no portal virtual da Câmara Municipal em 2020, apresentava algumas 
estratégias para o desenvolvimento das áreas rurais, com destaque para o inciso VI do Art. 45 que discorria sobre o "Programa de Promoção das Atividades Econômicas na Área Rural, com o objetivo de assegurar, com base no Zoneamento Ecológico Econômico, o desenvolvimento das atividades rurais ou as desenvolvidas no meio rural, apoiando e fomentando o sistema de produção e comercialização, com vistas ao desenvolvimento sustentável". Em relação ao ordenamento territorial apresentamse estratégias, de forma genérica, como visto no inciso II do Art.78. "Promoção do macrozoneamento do território municipal fundamentado nas características físicas e ambientais, respeitando-se as diversidades socioeconômicas e culturais e as tendências de ocupações urbanas e rurais", porém de forma mais "efetiva" relacionada ao ordenamento do solo rural pode observar a diretriz no Art. 181 "O ordenamento do solo rural objetiva promover o desenvolvimento econômico e sustentável nas macrozonas rurais do Município, com a regulação das atividades agropecuárias, agroturísticas, agroecológicas, ecoturísticas, de silvicultura, além daquelas previstas no Decreto Federal $n^{\circ}$ 62.504, de 8 de abril de 1968, em áreas específicas, a partir da definição das fragilidades e das potencialidades ambientais, respeitadas as áreas protegidas em leis municipais, estaduais e federais."(GOIÂNIA, 2018).

\section{Expansão da mancha urbana na RMG}

Analisando-se os dados de cobertura da mancha urbana com o uso do solo na Região Metropolitana de Goiânia para os anos de 1991, 2000 e 2010, 2020 tem-se a Figuras 4 e as Tabelas 1 e 2: 

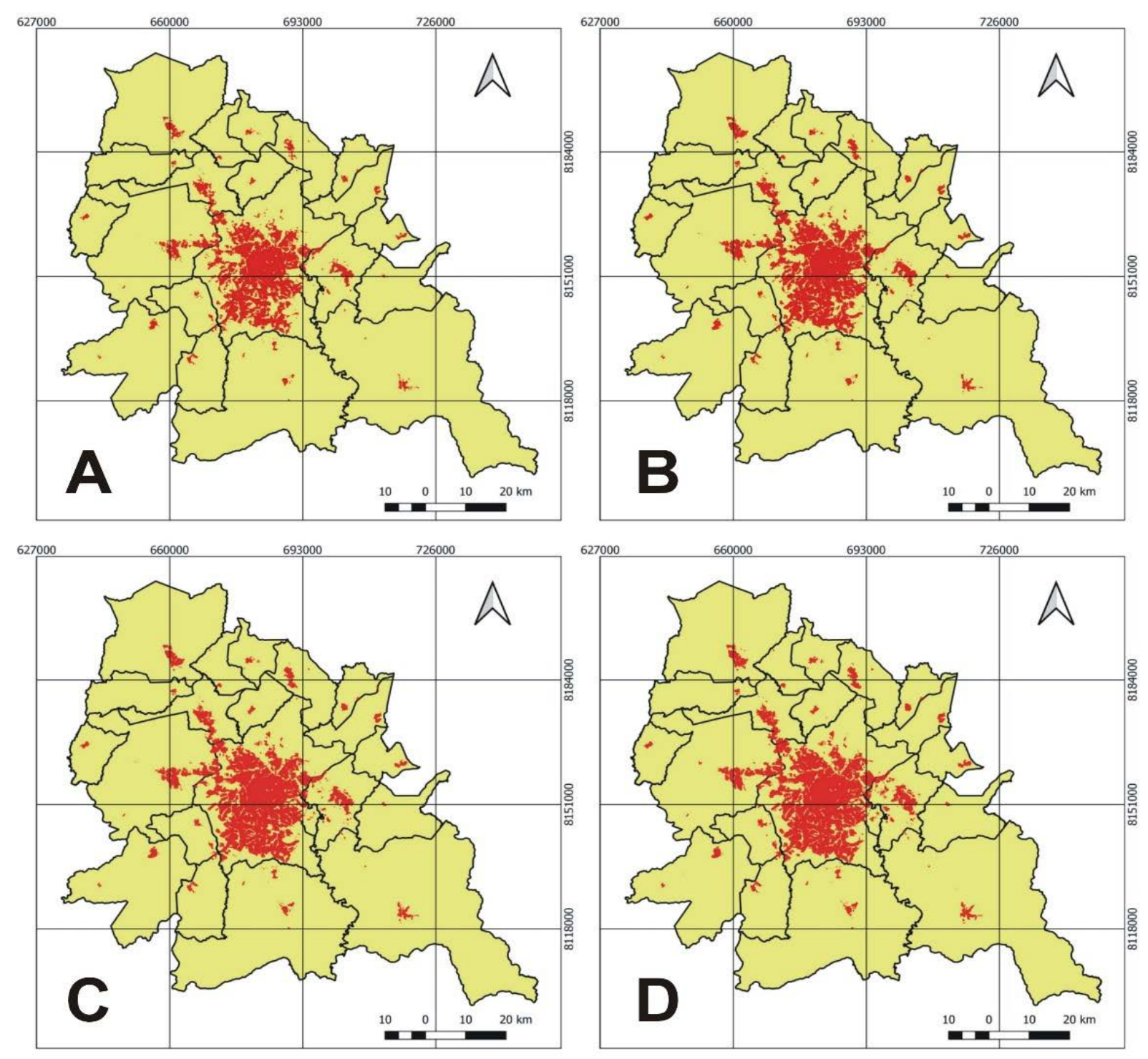

Projeção UTM

\section{Legenda}

Referêncial Geodésico WGS84

Hemisfério Sul

Região Metropolitana de Goiânia

Fuso 22

Mancha Urbana

Figura 4 -Mancha Urbana da RMG em 1991(A), 2000(B), 2010(C) e 2020(D). Fonte: SIEG e MAPBIOMAS. Adaptado pelos autores. 
Planejamento Territorial de Áreas Rurais em Contexto Metropolitano: o caso da RMG.

\begin{tabular}{lc|c|c|c}
\hline \multicolumn{1}{c}{ Município } & \multicolumn{4}{c}{ Mancha Urbana (km2) } \\
\hline & $\mathbf{1 9 9 1}$ & $\mathbf{2 0 0 0}$ & $\mathbf{2 0 1 0}$ & $\mathbf{2 0 2 0}$ \\
\hline Abadia de Goiás & 2,7 & 3,0 & 4,0 & 5,9 \\
\hline Aparecida de Goiânia & 107,4 & 124,8 & 135,8 & 139,2 \\
\hline Aragoiânia & 3,5 & 3,7 & 4,0 & 4,3 \\
\hline Bela Vista de Goiás & 5,0 & 6,6 & 7,9 & 9,0 \\
\hline Bonfinópolis & 2,2 & 2,9 & 3,1 & 3,4 \\
\hline Brazabrantes & 0,9 & 1,1 & 1,1 & 1,3 \\
\hline Caldazinha & 0,5 & 0,7 & 0,8 & 0,8 \\
\hline Caturaí & 1,2 & 1,4 & 1,5 & 1,6 \\
\hline Goianápolis & 2,3 & 3,2 & 3,4 & 3,7 \\
\hline Goiânia & 249,0 & 283,7 & 312,4 & 323,7 \\
\hline Goianira & 15,4 & 18,4 & 19,7 & 20,9 \\
\hline Guapó & 3,8 & 4,5 & 5,0 & 5,4 \\
\hline Hidrolândia & 4,9 & 5,6 & 7,4 & 8,2 \\
\hline Inhumas & 9,2 & 11,9 & 12,9 & 14,2 \\
\hline Nerópolis & 5,6 & 7,4 & 8,4 & 9,2 \\
\hline Nova Veneza & 1,9 & 2,3 & 2,6 & 3,0 \\
\hline Santa Bárbara de Goiás & 1,6 & 2,0 & 2,0 & 2,0 \\
\hline Santo Antônio de Goiás & 1,4 & 1,7 & 2,0 & 2,3 \\
\hline Senador Canedo & 20,1 & 24,2 & 29,8 & 38,6 \\
\hline Terezópolis de Goiás & 2,3 & 2,8 & 3,0 & 3,3 \\
\hline Trindade & 29,0 & 35,8 & 38,5 & 44,0 \\
\hline
\end{tabular}

Tabela 1- Área Total da Mancha Urbana da RMG Fonte: Elaborado pelos autores.

\begin{tabular}{lc|ccc}
\hline \multicolumn{1}{c}{ Município } & \multicolumn{4}{c}{ \% Mancha Urbana } \\
\hline & $\mathbf{1 9 9 1}$ & $\mathbf{2 0 0 0}$ & $\mathbf{2 0 1 0}$ & $\mathbf{2 0 2 0}$ \\
\hline Abadia de Goiás & 1,9 & 2,1 & 2,7 & 4,0 \\
\hline Aparecida de Goiânia & 38,6 & 44,8 & 48,8 & 50,0 \\
\hline Aragoiânia & 1,6 & 1,7 & 1,8 & 2,0 \\
\hline Bela Vista de Goiás & 0,4 & 0,5 & 0,6 & 0,7 \\
\hline Bonfinópolis & 1,8 & 2,4 & 2,5 & 2,8 \\
\hline Brazabrantes & 0,7 & 0,9 & 0,9 & 1,0 \\
\hline Caldazinha & 0,2 & 0,3 & 0,3 & 0,3 \\
\hline Caturaí & 0,6 & 0,7 & 0,7 & 0,8 \\
\hline Goianápolis & 1,4 & 1,9 & 2,0 & 2,2 \\
\hline Goiânia & 33,7 & 38,4 & 42,3 & 43,9 \\
\hline Goianira & 7,6 & 9,1 & 9,8 & 10,3 \\
\hline Guapó & 0,7 & 0,9 & 1,0 & 1,0 \\
\hline Hidrolândia & 0,5 & 0,6 & 0,8 & 0,9 \\
\hline Inhumas & 1,5 & 1,9 & 2,1 & 2,3 \\
\hline Nerópolis & 2,8 & 3,6 & 4,1 & 4,5 \\
\hline Nova Veneza & 1,5 & 1,9 & 2,1 & 2,4 \\
\hline Santa Bárbara de Goiás & 1,1 & 1,4 & 1,4 & 1,5 \\
\hline Santo Antônio de Goiás & 1,0 & 1,2 & 1,5 & 1,7 \\
\hline Senador Canedo & 8,2 & 9,9 & 12,1 & 15,8 \\
\hline Terezópolis de Goiás & 2,2 & 2,6 & 2,8 & 3,1 \\
\hline Trindade & 4,1 & 5,0 & 5,4 & 6,2 \\
\hline
\end{tabular}

Tabela 2- Relação \% da área da mancha urbana sobre a área total do município Fonte: Elaborado pelos autores. 
Os dados indicam revelam não o crescimento da mancha urbana entre 1991 e 2010 ao mesmo tempo em que se observa a redução da população rural, com destaque para os quatro municípios mais populosos da RMG: Goiânia, Aparecida de Goiânia, Trindade Senador e Canedo (Figura 5).

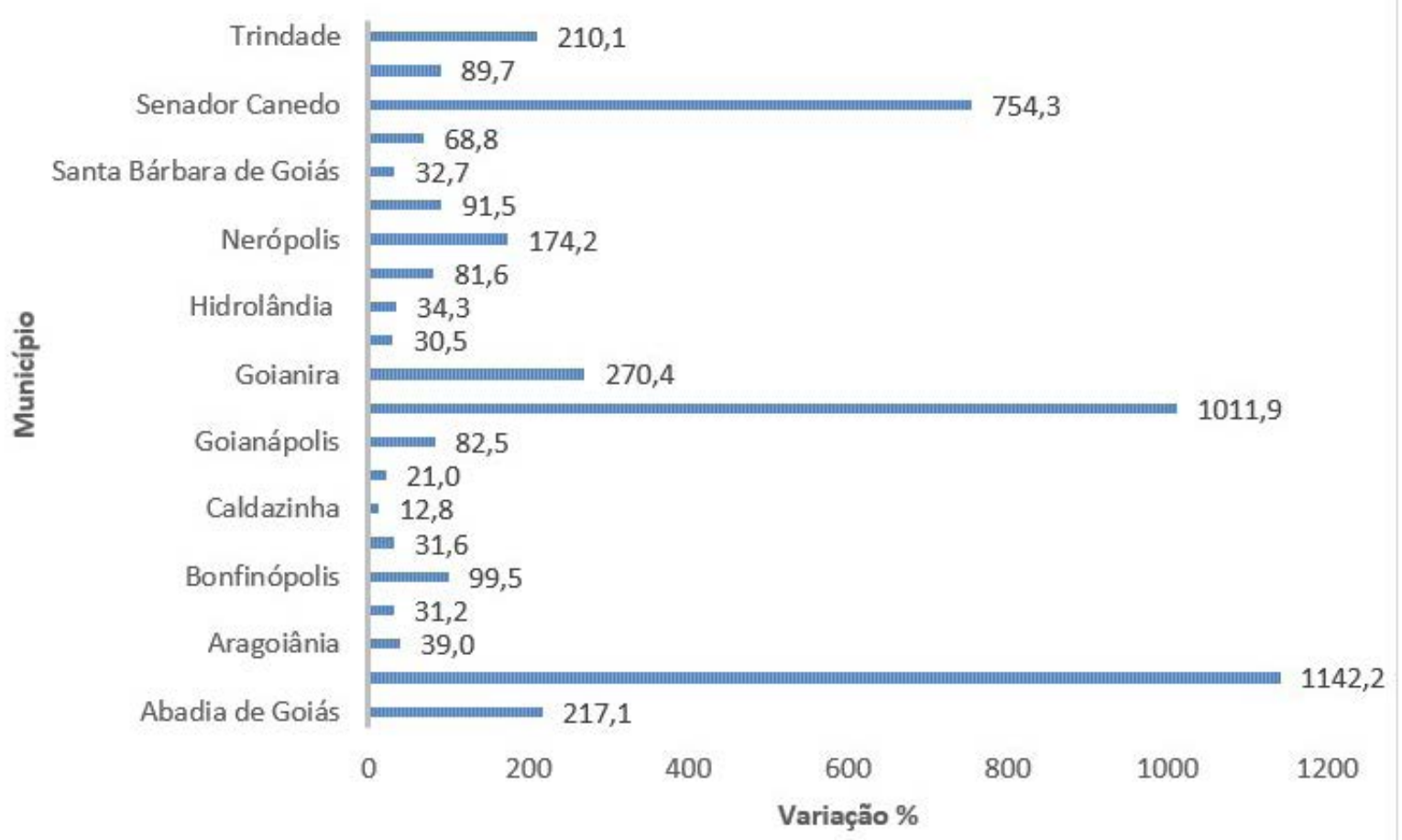

Figura 5 - Variação Percentual da Expansão da Mancha Urbana, entre os anos de 1991 e 2020. Fonte: Elaborado pelos autores.

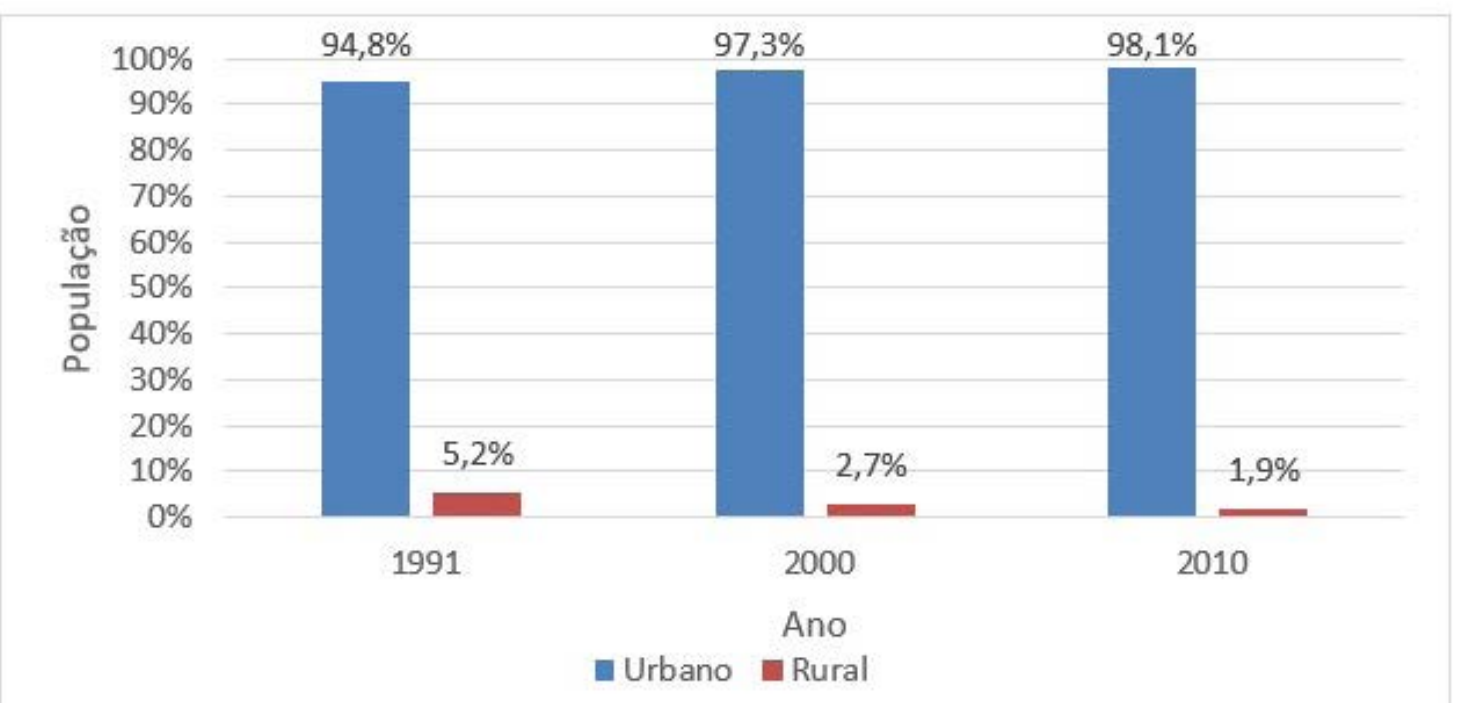

Figura 6 - Porcentagem da População Censitária Urbana e Rural na RMG, considerando a composição da RMG em 2021. Fonte: Elaborado pelos autores. 
Em relação a todo território da RMG o percentual de expansão da mancha urbana entre os anos de 1991 e 2010 foi de 33,8\%, enquanto a variação percentual da população censitária, entre 1991 e 2010 foi de 65\% em termos absolutos, saltando de 1,316 mi para 2,172 mi. Nesta linha de tendência, a população rural, considerando a RMG como um todo, segue reduzindo.

De acordo com o IBGE em 2017, as áreas urbanas e rurais não são identificáveis facilmente, especialmente por conta da grande interligação que tem ocorrido entre essas áreas em todo o cenário brasileiro. Os municípios devem definir os limites urbanos de seu território e toda área externa ao perímetro urbano é identificado como rural (MARQUES, 2019). É, nestas áreas que estão localizadas maior parte das áreas verdes remanescentes, tais como as matas e florestas que regulam os ciclos hidrológicos e protegem os cursos d'água, possibilitando baixos riscos de contaminação, protegendo o solo, melhorando a qualidade do ar e proporcionando ambientes agradáveis para a saúde humana.

Entretanto, ao se confrontar o crescimento urbano com os estudos de Nunes (2016), atualizando para 2020, observa-se que a ausência de controle e orientação para o crescimento urbano nas áreas rurais tendem a possibilitar o crescimento da mancha urbana sobre as estas e sem distinção, inclusive para as áreas de captação de água destinadas ao consumo humano (Figura 7).

A ausência de diretrizes para as franjas urbanas ou para as áreas de transição urbana-rural nos Planos Diretores Municipais seguem, assim, fragilizadas do ponto de vista institucional do planejamento urbano. A perspectiva do Estatuto da Metrópole ainda não se reverbera na RMG, revelando-se desafios para a gestão compartilhada das funções de uso comum e para uma gestão integrada do rural no contexto metropolitano. 


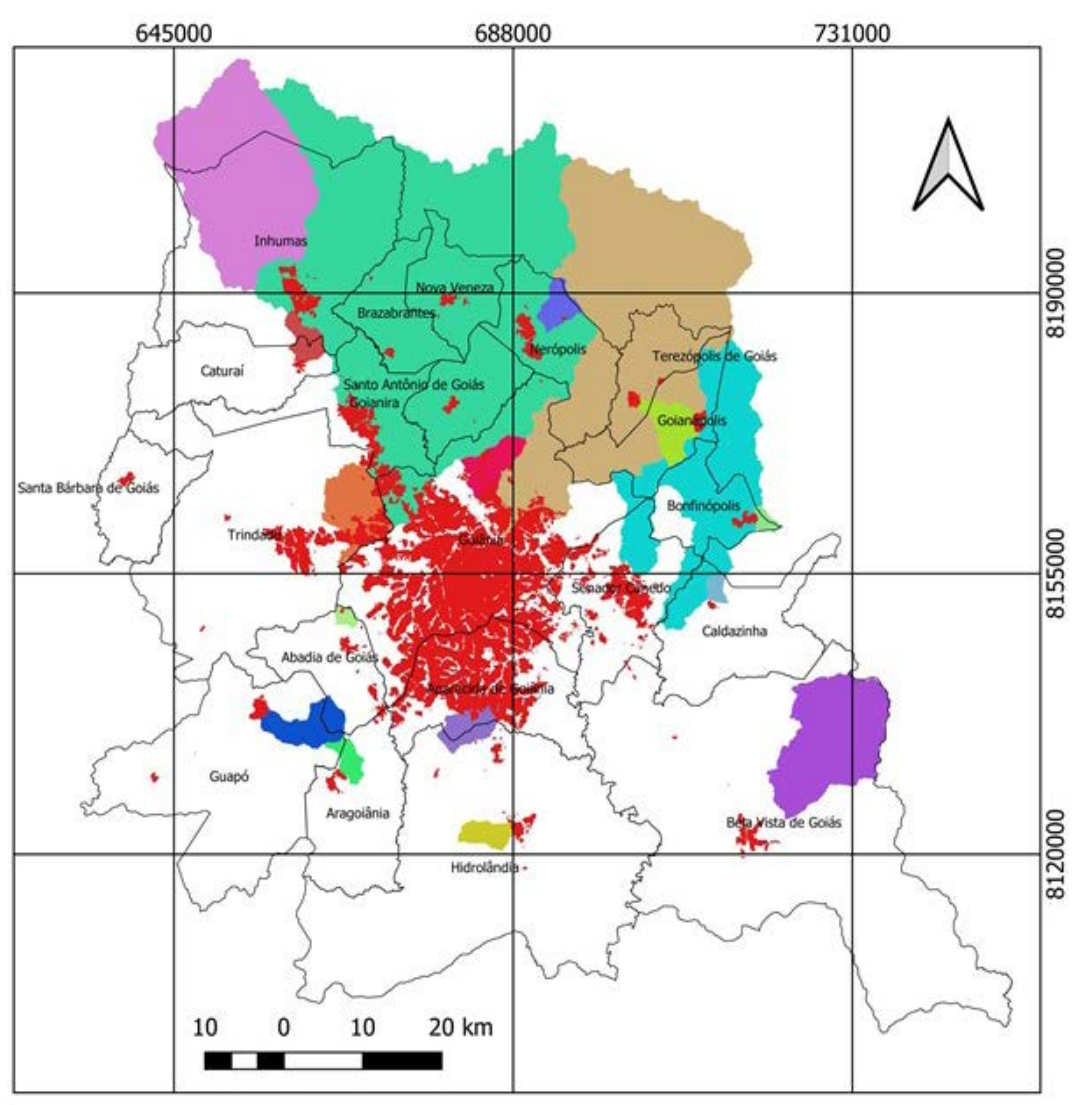

\title{
Bacias de Captção Superficial da RMG
}

\author{
Legenda \\ $\square$ Municípios RMG \\ 2020 \\ Bacias de Captação \\ Abadia de Goiás \\ - Aparecida de Goiânia \\ Aragoiânia \\ Bela Vista \\ Bonfinópolis \\ Brazabrantes \\ Caldazinha \\ Caturai \\ Goiânia João Leite \\ Goiânia Meia Ponte \\ - Goiânia Samambaia \\ Guapó \\ Hidrolândia \\ Inhumas \\ Nerópolis \\ - Senador Canedo \\ Terezópolis \\ Trindade \\ Projeção UTM \\ SIRGAS 2000 \\ Fuso 22 - Hemisfério Sul
}

Figura 7 - Mancha Urbana da RMG, 2020 e bacias de captação de água da RMG. Fonte:Nunes (2016). Atualizado pelos autores.

Ainda que, todos os Planos Diretores Municipais vigentes na RMG sejam anteriores ao Estatuto da Metrópoles e à Lei n॰ 12608 de 10 de abril de 2012 que criou o artigo 42-B do Estatuto da Cidade (ALBUQUERQUE; ALBUQUERQUE, 2017) alerta-se para a necessidade, não só de atualização do marco normativo-legal de planejamento urbano; mas, sobretudo, para a adoção de uma nova perspectiva de planejamento integrado das áreas urbano-rural no contexto metropolitano. Portanto, persiste-se o desafio em planejar as áreas rurais e as de transição urbano-rurais (MIRANDA, 2009) em contextos metropolitanos (HORA, 2017). 


\section{Considerações finais}

Este trabalho observou os Planos Diretores no contexto da Região Metropolitana de Goiânia visando averiguar as diretrizes e os instrumentos destinados ao planejamento das áreas rurais. A análise da expansão da mancha urbana no período de 1991-2020 denota ausência de ações que valorizem as áreas rurais no contexto investigado, podendo observar uma prevalência da expansão urbana desordenada sobre as áreas rurais, motivada pela inexistência de normativas relacionadas ao planejamento das áreas de franjas urbanas. A lógica do crescimento urbano e da política urbana desconsidera o potencial da multifuncionalidade desempenhada pelas áreas rurais.

A experiência do Plano Diretor Estratégico de São Paulo de 2014 abre uma nova referência ao planejamento das áreas rurais no contexto urbanizado. Soma-se a isto, a promulgação do Estatuto da Metrópoles, possibilidade a gestão das funções de uso comum.

Assim, o exercício de compartilhamento das funções de uso comum poderia ser aplicado, dentre diferentes aspectos. Entretanto, chama-se atenção para a gestão do uso da terra rural, cuja uma das funções poderia se ancorar na gestão dos recursos hídricos, subsidiada em leis tais como a PNMA e a PNRH.

Não obstante, compreender a singularidade das áreas rurais em contextos metropolitanos também implica considerar ações que evitem seu esvaziamento demográfico e possibilitem novas estratégias de produção, principalmente aquelas que considerem o abastecimento alimentar do mercado local e a segurança alimentar e nutricional. Ações como esta, devem retomar uma abordagem de desenvolvimento territorial do rural e articular novas perspectivas de integração e interdependência do campo-cidade em contextos altamente urbanizados. Para isto há que se criar cinturões verdes de produção protegidos nos macrozoneamentos da política urbana municipal.

Outros aspectos territoriais que poderiam ser somados à essa avaliação poderiam considerar o quantitativo dos estabelecimentos agropecuários e seus usos 
prioritários, verificando alterações no padrão de uso da terra para fins agropecuários, bem como a variação do preço da terra nas franjas urbanas. Além da discussão sobre parcelamentos rurais e agrários em contextos metropolitanos.

\section{Referências}

ALBUQUERQUE, P. C.; DE ALBUQUERQUE, M. P. A Ocupação Da Zona Rural Com Fins Urbanos: $O$ ordenamento territorial pelo município e a cidade sustentável. Revista de Direito Urbanístico, Cidade e Alteridade. Brasília. v. 3, n. 1. p. 36 - 57. Jan/Jun. 2017.

ALENTEJANO, P. R. As relações campo-cidade no Brasil do século XXI. In Revista de Políticas Públicas. v. 7, n. 2 (2003). Disponível em: http://www. periodicoseletronicos.ufma.br/index.php/rppublica/article/view/3749/1806 acesso em 02nov2021.

APARECIDA DE GOIÂNIA, Lei complementar $n^{\circ}$ 124. 14 de dezembro de 2016. Plano diretor do Município de Aparecida de Goiânia. Prefeitura Municipal de Aparecida de Goiânia. Goiás. 2016.

ASSIS, Renato Linhares de. Desenvolvimento rural sustentável no Brasil: perspectivas a partir da integração de ações públicas e privadas com base na agroecologia. Economia Aplicada [online]. 2006, v. 10, n. doi.org/10.1590/S141380502006000100005.

BRAGA, R. Plano diretor municipal: três questões para discussão. Caderno do Departamento de Planejamento, v. 1, n. 1, p. 15-20, 1995.

BRASIL. Constituição (1988). Constituição da República Federativa do Brasil. Brasília, DF: Senado Federal: Centro Gráfico, 1988. 292 p.

BRASIL. Estatuto da Metrópole. Lei no 13089 de 12 de janeiro de 2015. Disponível em: http://www.planalto.gov.br/ccivil_03/_ato2015-2018/2015/lei//13089.htm. Acesso em 15set2021

BRASIL. Estatuto da Cidade. Lei $\mathbf{n}^{\circ} 10257$ de 10 de julho de 2001. Disponível em: http://www.planalto.gov.br/ccivil_03/leis/leis_2001/l10257.htm. Acesso em 15set2021

BRASIL. Estatuto da Terra. Lei ${ }^{\circ}$ 4.504, de 30 de novembro de 1964. Disponível: http://www.planalto.gov.br/ccivil_03/leis//4504.htm. Acesso em 15set2021

BRASIL. Política Nacional de Meio Ambiente. Lei $n^{\circ} 6.938$, de 31 de agosto de 1981. Disponível em: http://www.planalto.gov.br/ccivil_03/leis/l6938.htm. Acesso em 15 set2021 
BRASIL. Política Nacional de Recursos Hídricos. Lei $n^{\circ}$ 9.433, de 8 de janeiro de 1997. Disponível: http://www.planalto.gov.br/ccivil_03/leis//9433.htm. Acesso em 15 set2021

BRASIL. Zoneamento Ecológico-Econômico. Decreto $n^{\circ} 4.297$, de 10 de julho de 2002. Disponível: http://www.planalto.gov.br/ccivil_03/decreto/2002/d4297.htm. Acesso em 15set2021.

CAMARGO, Regina Aparecida Leite de; OLIVEIRA, Julieta Teresa Aier de. Agricultura familiar, multifuncionalidade da agricultura e ruralidade: interfaces de uma realidade complexa. Ciência Rural [online]. 2012, v. 42, n. 9. /doi. org/10.1590/S0103-84782012005000068.

CARDOSO, Renan Telles; EMPINOTTI, Vanessa Lucena; TRAVASSOS, Luciana. O ressurgimento da zona rural no município de São Paulo. XVII ENAPUR: Desenvolvimento, Crise e Resistência: Quais os Caminhos do Planejamento Urbano E Regional?. São Paulo, 2017.

CONCEIÇÃO, Luciane A. B. S. Diagnóstico Ambiental Através Do Uso De Técnicas De Sensoriamento Remoto Como Apoio Para O Planejamento De Unidades Administrativas: O Caso De Osório, Rs. Universidade Federal Do Rio Grande Do Sul. Porto Alegre, 2004, 72p.

CONCEIÇÃO, Fabrícia Carlos da. Multifuncionalidade e Pluriatividade Rural: uma revisão bibliográfica. Revista Tocantinense de Geografia Araguaína v. 10, n. 18 mai.-Agost/2020, pg. 103-2012

DEUS, João Batista de; BARREIRA, Celene C. M. Antunes. A experiência de formulação e desenvolvimento do Plano de Desenvolvimento Integrado da Região Metropolitana de Goiânia: reflexões preliminares e indagações metodológicas. In: XI-ENCONTRO NACIONAL DA ANPEGE, 2015, São Paulo.

DIAS, Daniella Maria dos Santos. Planejamento e desenvolvimento urbano no sistema jurídico brasileiro: óbices e desafios. Curitiba: Juruá, 2012, p. 56.

DRUCKER, Peter F. Introdução à Administração. São Paulo, Editora Pioneira Thomson, 2002.

FAVARETO, Arilson A abordagem territorial do desenvolvimento rural-mudança institucional ou "inovação por adição"?. Estudos Avançados [online]. 2010, v. 24, n. 68 doi.org/10.1590/S0103-40142010000100021.

GIRARDI, Eduardo Paulon. Proposição teórico-metodológica de uma cartografia geográfica crítica e sua aplicação no desenvolvimento do atlas da questão agrária brasileira. Tese (doutorado) - Universidade Estadual Paulista, Faculdade de Ciências e Tecnologia, 2008. Disponível em: < http://hdl.handle.net/11449/105064 >.

GOIÁS. Lei Complementar № 149, de 15 de maio de 2019. Dispõe sobre a Região Metropolitana de Goiânia. Disponível em: <http://www.gabinetecivil.go.gov.br/pagina_ leis. php?id=23575> Acesso em nov. de 2019. 
GOIÂNIA. Minuta de Lei do plano Diretor de Goiânia de 19 de fevereiro de 2018 que dispõe sobre o plano diretor do Município de Goiânia (Altera a Lei ${ }^{\circ} 171$, de 29 de maio de 2007). Prefeitura Municipal de Goiânia. Goiás. 2018.

GRAZIANO SILVA, José. O novo rural brasileiro. 2a . Edição. Campinas: Unicamp. 2002. Disponível em: https://www.eco.unicamp.br/images/publicacoes/Livros/ pesquisa/O-novo-rural-Brasileiro.pdf. Acesso em 02nov2021

HIDROLÂNDIA. Lei $\mathbf{n}^{\circ}$ 288. 13 de dezembro de 2006. Plano diretor do Município de Hidrolândia. Prefeitura de Hidrolândia. Goiás. 2006.

HORA, Karla E. R. O lugar das águas na Região Metropolitana de Goiânia. In: I Seminário de Paisagem Urbana e Sustentabilidade. Anais: UFG. Goiânia, Gráfica UFG, 2017, p. 88-105

HORA; K. E. R; ROESLER, D. A.; FRANCO, J. G. de O.; MAYER, P. H. Limites e potencialidades para o desenvolvimento do rural numa perspectiva socioambiental: um estudo em comunidades no sul da Região Metropolitana de Curitiba - RMC. UFPR, 2007. Disponível em <http://anppas.org.br/encontro4/cd/ ARQUIVOS/GT1-875-797-20080510204217.pdf> Acesso em jun. de 2018.

IBGE. Classificação e caracterização dos espaços rurais e urbanos do Brasil: uma primeira aproximação. Rio de Janeiro, IBGE - Coordenação de Geografia, 2017.

IBGE. Instituto Brasileiro de Geografia e Estatística. Censo Demográfico 2010. Disponível: www.ibge.gov.br .

LIMA, D. F, et al. Instrumentos de Planejamento e Ordenamento Territorial: Um Olhar Para Municípios Norte-Riograndenses. In: Congresso Técnico Científico da Engenharia e da Agronomia CONTECC 2016. Paraná. 2016. Disponível em: <http://www.confea.org.br/media/contecc2016/civil/instrumentos\%20de\%20 planejamento\%20e\%20ordenamento\%20territorial\%20um\%20olhar\%20para\%20 munic\%C3\%ADpios\%20norte-riograndenses.pdf> Acesso em: jun de 2018.

LUFT, Rosangela M. Questões pontuais na elaboração do Plano Diretor: planejamento urbano e factibilidade ética. Revista da Faculdade de Direito da UERJ, v. 1, p. 01-18, 2010.

MARQUES, A. L. Franjas metropolitanas e as dimensões da sustentabilidade: o caso da sub-bacia Juqueri-Cantareira da região metropolitana de São Paulo. Dissertação (Arquitetura e Urbanismo) - Universidade Presbiteriana Mackenzie. São Paulo, 2019. 163 f. Disponível em: <http://tede.mackenzie.br/jspui/handle/tede/4079> Acesso em: nov. de 2019.

KOZENIESKI, Éverton de M. K.; MEDEIROS, Rosa. V. O rural agrícola na metrópole: o caso de Porto Alegre/RS. Revista franco-brasilera de geografia, v. 35, 2018. DOI: https://doi.org/10.4000/confins.13167. 
MALUF, Renato. Plano Diretor Rural, estratégias de desenvolvimento rural e Política Municipal de Segurança Alimentar e Nutricional em Piracicaba. In: SANTORO, P.; PINHEIRO, E. (Org.). O planejamento do município e o território rural. São Paulo: Instituto Pólis, 2004, p. 37- 40.

MESQUITA, P. A., FERREIRA, R. W. O Rural No Planejamento Municipal: O Plano Diretor Municipal Como Instrumento De Planejamento Rural. Espaço em Revista, v.18, n.1, p. 11-32 jan/jun, 2016.

MIRANDA; LÍVIA Izabel B. de. Planejamento em áreas de transição rural-urbana: velhas novidades em novos territórios. Revista Brasileira de Estudos Urbanos e Regionais v. 11, n.1/ maio. 2009. pg 25 a 40

NERÓPOLIS. Lei $n^{\circ} 1.777$ de. 07 de julho de 2015, altera a Lei $n^{0} 1.472$ de 29 de dezembro 2008 que: Institui o Plano Diretor Democrático do Município de Nerópolis e dá outras providências.

NUNES, Isis Terra Portella Conde Cardeliquio. Avaliação do Crescimento Urbano sobre os Mananciais Superficiais de Captação de Água e Demanda Hídrica na Região Metropolitana de Goiânia (RMG). Trabalho Conclusão de Curso. Goiânia: UFG/EECA, 2016.

PÁDUA, José Augusto. Aniquilando as naturais produções": crítica iluminista, crise colonial e as origens do ambientalismo político no Brasil (17861810),1999, v. 42, n. 3. doi.org/10.1590/S0011-52581999000300005.

SANTOS, Juliana Vamerlati; FERREIRA, Rodrigo Cornacini. Planejamento Ambiental. Curitiba-PR, 2011. Instituto Federal do Paraná para o Sistema Escola Técnica Aberta do Brasil - e-Tec Brasil.

SANTOS, R. F. Planejamento Ambiental: teria e prática. São Paulo: Oficina de Textos. 2004.

SÃO PAULO. Lei no 16.050, de 31 de julho de 2014. Política de Desenvolvimento Urbano e o Plano Diretor Estratégico do Município de São Paulo. Disponível em: $<$ https://gestaourbana.prefeitura.sp.gov.br/arquivos/PDE-Suplemento-DOC/PDE_ SUPLEMENTO-DOC.pdf> Acesso em: nov. de 2019.

SAULE JÚNIOR, Nelson. A competência do Município para disciplinar o território rural. In: SANTORO, Paula; PINHEIRO, Edie (Org.). O planejamento do município e o território rural. (Cadernos Pólis, 8). São Paulo: Instituto Pólis, 2004. p. 41-52.

SILVA, G. O imaginário rural do leitor urbano: o sonho mítico da casa no campo. 2000. 244f. Tese (Doutorado em Antropologia) - Programa de Estudos Pósgraduados em Ciências Sociais, Pontifícia Universidade Católica, São Paulo, 2000.

SOROKIN. P; ZIMMERMAN,C;GALPIN,C. Diferenças fundamentais entre o mundo rural e o urbano. In: MARTINS, José de Souza. (org.) Introdução critica a Sociologia Rural. São Paulo: HUCITEC, 1981. 
SPAROVEK, G.; LEONELLI, G. C. V.; BARRETTO, A. G. O. P. A linha imaginária. In: SANTORO, P.; PINHEIRO, E. (Org.). O planejamento do município e o território rural. São Paulo: Instituto Pólis, 2004, p. 14-24.

VEIGA, José Eli da. Cidades Imaginárias: O Brasil é menos urbano do que se calcula. Campinas - São Paulo: Editores Associados, 2002

WANDERLEY, Maria Nazareth Baudel. A emergência de uma nova ruralidade nas sociedades modernas avançadas - 0 "rural" como espaço singular e ator coletivo. Estudos Sociedade e Agricultura, Rio de Janeiro, n.15, p.87-145, 2000.

GOLDFARB, Yamila. A luta pela terra entre o campo e a cidade: as comunas da terra do MST, sua gestação, principais atores e desafios. 2007. Dissertação (Mestrado em Geografia Humana) - Faculdade de Filosofia, Letras e Ciências Humanas, Universidade de São Paulo, São Paulo, 2007. doi:10.11606/D.8.2007.tde02012008-112829. Acesso em: 2021-09-08.

ZARREF, Luiz. Questão ambiental e territorialização do Capital: novas formas de acumulação capitalista. Tese Doutorado. Goiânia: UFG/IESA, 2017.

\section{NOTAS}

\section{Publisher}

Universidade Federal de Goiás. Faculdade/Instituto/Escola. Programa de Pós-graduação Projeto e Cidade. Publicação no Portal de Periódicos UFG. As ideias expressadas neste artigo são de responsabilidade de seus autores, não representando, necessariamente, a opinião dos editores ou da universidade.

RECEBIDO EM: 10/10/2021

APROVADO EM: 08/12/2021

PUBLICADO EM: 30/12/2021 